\title{
Effect of Low-Intensity Exercise on Oxidative Stress, Inflammatory and Nutritional Responsiveness in Sedentary People
}

\author{
Kultida Klarod ${ }^{1}$, Pranithi Hongsprabhas ${ }^{2}$, Tistaya Samangeon ${ }^{3}$, Krittika Hongto ${ }^{1}$, Roongpet \\ Tangrassameeprasert ${ }^{4}$, Patcharee Boonsiri ${ }^{4}$ and Martin Burtscher ${ }^{5 *}$ \\ ${ }^{1}$ Department of Physical Therapy, Faculty of Allied Health Science, Burapha University, Chonburi 20131, Thailand \\ ${ }^{2}$ Department of Medicine, Faculty of Medicine, Khon Kaen University, Khon Kaen 40002, Thailand \\ ${ }^{3}$ Department of Medical Technology, Faculty of Allied Health Science, Burapha University, Chonburi 20131, Thailand \\ ${ }^{4}$ Department of Biochemistry, Faculty of Medicine, Khon Kaen University, Khon Kaen 40002, Thailand \\ ${ }^{5}$ Department of Sport Science, Faculty of Psychology and Sport Science, University of Innsbruck, Innsbruck 6020, Austria
}

Received: February 07,2017; Accepted: February 25,2017; Published: March 10, 2017

*Corresponding author: Martin Burtscher, Department of Sport Science, Faculty of Psychology and Sport Science, University of Innsbruck, Innsbruck 6020, Austria, Tel: (+43) 0512507 45896; E-mail: Martin.Burtscher@uibk.ac.at

\begin{abstract}
Adaptation to exercise-induced detrimental effect of reactive oxygen species from endurance exercise is crucial for sedentary people. Thus, our study aimed to investigate the effects of lowintensity exercise training on oxidative stress level, inflammatory responses and nutritional status in young sedentary people. Participants performed low-intensity exercise by cycling at a target heart rate of $40 \%$ heart rate reserve for 8 weeks (once/ day, 3 days/ week). Nutritional status and blood samples were collected before the exercise sessions at the beginning, and 4 and 8 weeks after training for determination of oxidative stress marker as malondialdehyde (MDA), muscle damage marker as creatine kinase (CK), inflammatory marker as high-sensitivity C-reactive protein (hs-CRP), nutritional response and other laboratory analysis. We demonstrated significantly reduced MDA levels after an exercise session at the beginning $(p=0.002)$ after $4(p<0.001)$ and after 8 weeks $(p<0.001)$ of training, when compared to pre-exercise. Besides, after exercise training, lactate concentration was significantly lower after $4(p=0.009)$ and $8(p=0.004)$ weeks of training. Hs-CRP levels tended to be highest after exercise at the beginning of training followed by a decline after training. We found positive correlations between hs-CRP level, lipids and body compositions ( $\mathrm{r}=0.75, p<0.001)$. No training-related differences were found with regard to nutritional status and lipid and lipoprotein levels. Thus, low-intensity exercise training may not affect lipid and lipoprotein levels and nutritional status, but causes a decline in oxidative stress levels.
\end{abstract}

Keywords: Body composition; Endurance exercise; High sensitivity C-reactive protein; Lactate concentration; Malondialdehyde; Nutrition; Young sedentary

\section{Abbreviations}

BMI: Body Mass Index; BHT: Butylated Hydroxyl Toluene; CV: Cofficient of Variation; CK: Creatine Kinase; EDTA: Ethylenediamine Tetraacetic Acid; HRR: Heart Rate Reserve;
HDL-C: High-Density Lipoprotein Cholesterol; Hs-CRP: High Sensitivity C-Reactive Protein; IQR: Interquartile Range; LDL-C: Low-Density Lipoprotein Cholesterol; MDA: Malondialdehyde; ROS: Reactive Oxygen Species; SDS: Sodium Dodecyl Sulfate; SD: Standard Deviation; TBA: Thiobarbituric Acid; TBARS: Thiobarbituric Reactive Substances; TCA: Trichloroacetic Acid; $\mathrm{VO}_{2}$ Max: Maximal Oxygen Consumption; WHR: Waist to Hip Ratio; WHO: World Health Organization

\section{Introduction}

Exercise is believed to have important benefits for patients in rehabilitation programmes [1]. Exercise is commonly recommended for improving muscle mass, muscle strength and muscle endurance, especially in people with chronic diseases [1]. During an exercise session there is an increase in consumption of oxygen, especially when performing endurance exercise. However, exhaustive exercise could lead to muscle cell damage and inflammation, which has been demonstrated by the augmentation of sarcolemma disruption [2]. Nevertheless, regular exercise likely improves defence against reactive oxygen species (ROS) by influencing adaptive effects in antioxidant and repair mechanisms [3].

Chronic exercise has been reported to extend the lifespan in both rodents and humans [4,5]. Muscle cells show adaptive responses to free radicals produced during the contraction process. This response is an increase in the antioxidant protection mechanism. Subsequently, the cells are able to deal better with regular ROS consequences [6]. In addition, it has been suggested that exercise training provokes anti-inflammatory effects, which seem to be associated with the generation of an antioxidative defence system that appears to reduce the C-reactive protein (CRP) level [7]. Different types of exercise training, however, 
have been shown to affect CRP levels differently [8]. Thus, it is crucial for sedentary people to acclimatize to exercise-induced detrimental effects from ROS and inflammatory responses during exercise. The intensity, time and type of exercise should be taken into consideration for this particular group of individuals.

Another important factor that should be taken into account during exercise is the individual nutritional status. For instance, obesity has been reported to impact on inflammatory-related oxidative stress [9]. Nutritional measures during the exercise programme should be adjusted to muscle type and exercise intensity. Nutritional alternatives affect the rates of fat oxidation (40-65\% of maximal oxygen consumption; $\mathrm{VO}_{2} \max$ ) during submaximal exercise [10]. Environmental factors are strongly involved in the alteration of nutritional use, such as during exercise in different cold and hot temperatures [11]. At high altitude, carbohydrates are preferentially used during exercise due to the lack of oxygen [12].

Based on all the aforementioned indications, we hypothesized that low-intensity exercise training in sedentary people should prevent detrimental effects from oxidative stress and inflammatory responses and should impact favourably on nutritional status. Thus, the present study aimed to investigate the effects of low-intensity exercise training on oxidative stress level, inflammatory responses and nutritional status in sedentary people.

\section{Methods}

\section{Participants}

Twenty undergraduate students ( 17 females and 3 males with an age range of 19 to 23 years) studying at Burapha University, Bangsean, Chonburi province, Thailand were enrolled for this study. Inclusion criteria were: subjects refraining from exercise for at least 3 months before taking part in the study; who did not use antioxidant supplementation; who did not suffer from diseases not compatible with low-intensity exercise training; and who were not smokers or drank alcohol on a regular basis. Nutritional status assessed by body composition was recorded including body weight, height, body fat, lean body mass and Waist to Hip Ratio (WHR). All participants provided informed written consent. The study was reviewed and approved by the Burapha University Human Ethics Institutional Review Board.

\section{Intervention}

Participants performed low-intensity exercise training by cycling. Starting with a warm-up for 2-3 minutes, subjects continued by cycling for $20 \mathrm{~min}$, increasing the workload until the target heart rate was $40 \%$ of the heart rate reserve (HRR). They could pause for 2 minutes during exercise. Heart rate was monitored for the entire exercise session. The target heart rate was calculated based on the Karvonen equation [Target heart rate $=$ (intensity fraction) $\mathrm{x}$ (maximal heart rate-resting heart rate) + resting heart rate] [13]. The exercise training programme lasted for 8 weeks (once/day, 3 days/week). Blood samples were collected before exercise, after an exercise session at the beginning of training (acute exercise), and after 4 and 8 weeks of training.

\section{Nutritional status assessment}

Weight and height were measured and calculated as body mass index (BMI); weight (kilograms; kg) was divided by the square of height in meters. BMI was classified according to the World Health Organization (WHO) criteria for Asian and Pacific populations (underweight $<18.5$, healthy $18.5-22.9$, at risk 2324.9 , obese I $25-29.9$ and obese II $\geq 30 \mathrm{~kg} / \mathrm{m}^{2}$ ) [14].

Percentage of body fat was evaluated by bioelectric impedance analysis (Tanita UM051, Tanita Corporation, Japan). Lean body mass was calculated by body weight $(\mathrm{kg})$ minus body fat $(\mathrm{kg})$ and presented as protein mass $(\mathrm{kg})$.

WHR was taken as a central obesity assessment. Waist circumference was measured in centimetres using a measuring tape at the midpoint between the lower ribcage and the iliac crest. Hip circumference was measured at the widest level around the buttocks. The WHR was calculated as waist circumference divided by hip circumference [15].

\section{Laboratory analysis}

The samples were transferred to sodium fluoride for plasma lactate concentration analysis, Ethylenediamine Tetraacetic Acid (EDTA) tube for Malondialdehyde (MDA) analysis, and clot blood tube for other biochemical analyses. They were separated by centrifugation. Then, transferred on ice and immediately measured by National Healthcare system (Samitivej Sriracha Hospital) and Chonburi Hospital. High-sensitivity C-reactive protein; hs-CRP, creatine kinase; CK, cholesterol, high-density lipoprotein cholesterol; HDL-C, triglyceride; TG levels (Olympus automated chemistry analyser SOP AU 400, within- and betweenrun coefficient of variation (\%CV) was $3 \%$ for all analyses) and regarding lactate concentration (Roche Cobas 6000 c501 module), within-run $\% \mathrm{CV}$ was below $5 \%$ and between-run below $10 \%)$. Low-density lipoprotein cholesterol; LDL-C was calculated using the Friedwald equation [16]. Blood plasmas were kept at $-20 \stackrel{\circ}{ } \mathrm{C}$. Then, MDA was measured.

Determination of MDA level by thiobarbituric reactive substances (TBARS): MDA was measured by thiobarbituric acid reactive substance (TBARS) assay modified from Nielsen et al. and Tsai et al. $[17,18]$. One millilitre of diluted plasma (1:2) was added with $50 \mu \mathrm{l}$ of $0.1 \mathrm{mM}$ butylated hydroxyl toluene (BHT), $500 \mu \mathrm{l}$ of $5 \mathrm{mM}$ EDTA, $1 \mathrm{ml}$ of $8.1 \%$ (w/v) sodium dodecyl sulfate (SDS), $1 \mathrm{ml}$ of $10 \%(\mathrm{w} / \mathrm{v}$ ) trichloroacetic acid (TCA) and $1.5 \mathrm{ml}$ of $0.67 \%(\mathrm{w} / \mathrm{v})$ thiobarbituric acid (TBA). The reaction mixture was incubated at $95{ }^{\circ} \mathrm{C}$ for $30 \mathrm{~min}$, and then dipped into tap water for $5 \mathrm{~min}$. After stopping the reaction, it was centrifuged at 3,000 rpm for $15 \mathrm{~min}$ at room temperature. The supernatant was transferred to a glass cuvette for measuring absorbance at 532 $\mathrm{nm}$. Tetraethoxypropane was used as standard in a concentration range of $0.25-2 \mu \mathrm{M}$.

\section{Statistical Analysis}

Normally distributed data are shown as mean \pm standard deviation (SD). Not normally distributed data are expressed as median (interquartile range; IQR). The distribution of data was 
tested by Kolmogorov-Smirnov test or Shapiro-Wilk test. ANOVA or the Kruskal-Wallis test with post hoc analysis (Bonferroni corrected) was used to compare differences among trials. Bivariate correlation analyses were performed using Pearson or Spearman's rank correlation as appropriate. Changes in MDA and lactate concentration levels between after an exercise session at the beginning of training (acute exercise) and after 4 weeks of training were calculated as after 4 weeks of training minus acute exercise values ( $\Delta$ Four-Acute), and between after an exercise session at the beginning of training (acute exercise) and after 8 weeks of training, presented as after 8 weeks of training minus acute exercise values ( $\Delta$ Eight-Acute), respectively. A $p<0.05$ was considered statistically significance. All statistical analyses were performed using the 17.0 version of the SPSS program (SPSS Inc., Chicago, IL).

A statistical power analysis was performed for sample size estimation, in regard to published study of Sekeroglu et al. [19] ( $N=15$ / group), comparing before exercise to after training. The effect size in this study was 2.64, which it was considered to be large effects based on Cohen's criteria [20]. With an alpha at 0.05 and power at 0.80 using ANOVA test, the present study's sample size with large effect size ( $\mathrm{f}=0.40$ ) was $\mathrm{N}=19$ people/ group (G*Power 3.1). Thus, our sample size of 20 people/ group will be competent for main objective of present study and should be adequate for our additional objectives for other parameters.

\section{Results}

Twenty healthy sedentary volunteers were enrolled for the present study. Their mean age was 19.9 (range 19-23) years. They were all non-smokers and did not drink alcohol. All participants were students of undergraduate level. Their baseline characteristics are shown in table 1 . There were no significant differences in lipid and lipoprotein levels or body composition between the exercise training time points, as presented in tables 2 and 3 , respectively.

MDA level had significantly dropped after an exercise session at the beginning of training $(p=0.002)$ after $4(p<0.001)$ and

Table 1: Baseline characteristic of sedentary people

\begin{tabular}{|c|c|}
\hline Characteristics & $\mathbf{N}=\mathbf{2 0}$ \\
\hline Age (years) [median (IQR)] & $20(19-23)$ \\
\hline Gender, N (\%) & \\
\hline Male & $3(15 \%)$ \\
Female & $17(85 \%)$ \\
\hline Occupation, N (\%) & Student $(100 \%)$ \\
\hline Education, N (\%) & Undergraduate $(100 \%)$ \\
\hline Tobacco smoking, N (\%) & None \\
\hline Alcohol drinking, N (\%) & None \\
\hline Body mass index (kg/m²) & $20.9 \pm 4.1$ \\
\hline Weight (kgs) & $54.3 \pm 11.6$ \\
\hline Body fat (kgs)* & $13.8 \pm 6.1$ \\
\hline Lean body mass (kgs)* & $40.6 \pm 7.5$ \\
\hline Waist to hip ratio* & $0.79 \pm 0.1$ \\
\hline *Values are expressed as mean \pm SD. IQR $=$ interquartile range. \\
\hline
\end{tabular}

\begin{tabular}{|c|c|c|c|c|}
\hline $\begin{array}{l}\text { Exercise periods } \\
\qquad(\mathrm{N}=20)\end{array}$ & $\begin{array}{l}\text { Cholesterol } \\
\text { (mg/dL) }\end{array}$ & $\begin{array}{c}\text { HDL-C } \\
(\mathrm{mg} / \mathrm{dL})\end{array}$ & $\begin{array}{c}\text { LDL-C } \\
(\mathrm{mg} / \mathrm{dL})\end{array}$ & $\begin{array}{c}\text { TG } \\
(\mathrm{mg} / \mathrm{dL})\end{array}$ \\
\hline Pre-exercise & $203 \pm 33$ & $57 \pm 10$ & $134 \pm 30$ & $60 \pm 16$ \\
\hline $\begin{array}{l}\text { After an exercise } \\
\text { session at the } \\
\text { beginning of training }\end{array}$ & $203 \pm 34$ & $59 \pm 9$ & $130 \pm 30$ & $71 \pm 22$ \\
\hline $\begin{array}{l}\text { After } 4 \text { weeks of } \\
\text { training }\end{array}$ & $202 \pm 30$ & $56 \pm 10$ & $131 \pm 28$ & $73 \pm 24$ \\
\hline $\begin{array}{l}\text { After } 8 \text { weeks of } \\
\text { training }\end{array}$ & $202 \pm 36$ & $57 \pm 12$ & $131 \pm 34$ & $70 \pm 20$ \\
\hline
\end{tabular}

Values are expressed as mean \pm SD. There are no significant differences between exercise time points

\begin{tabular}{|c|c|c|c|c|c|}
\hline \multicolumn{7}{|c|}{ Table 3: Nutritional status assessed by body compositions } \\
\hline $\begin{array}{c}\text { Exercise } \\
\text { periods }\end{array}$ & $\begin{array}{c}\text { BMI } \\
\text { (kgs/ }\end{array}$ & $\begin{array}{c}\text { Weight } \\
\text { (N) 20) }\end{array}$ & $\begin{array}{c}\text { Body fat } \\
\text { (kgs) }\end{array}$ & $\begin{array}{c}\text { Lean } \\
\text { body }\end{array}$ & WHR \\
mass & WHR \\
(kgs) & \\
\hline
\end{tabular}

\begin{tabular}{l|l|l|l|l|l} 
Pre-exercise & $20.9 \pm 4.1$ & $54.3 \pm 11.6$ & $13.8 \pm 6.1$ & $40.6 \pm 7.5$ & $0.79 \pm 0.1$
\end{tabular}

After an exercise

session at

\begin{tabular}{l|l|l|l|l|l} 
the beginning of & $20.5 \pm 3.9$ & $53.4 \pm 11.2$ & $13.7 \pm 5.6$ & $39.6 \pm 7.3$ & $0.78 \pm 0.1$
\end{tabular} training \begin{tabular}{|c|c|c|c|c|c}
$\begin{array}{c}\text { After } 4 \text { weeks of } \\
\text { training }\end{array}$ & $20.7 \pm 4.1$ & $53.8 \pm 11.6$ & $13.9 \pm 6.0$ & $39.8 \pm 7.3$ & $0.77 \pm 0.1$
\end{tabular}

\begin{tabular}{|c|c|c|c|c|c}
\hline $\begin{array}{c}\text { After } 8 \text { weeks of } \\
\text { training }\end{array}$ & $20.6 \pm 4.0$ & $53.7 \pm 11.4$ & $13.9 \pm 6.0$ & $39.8 \pm 7.1$ & $0.76 \pm 0.1$
\end{tabular} training

Values are expressed as mean \pm SD. There are no significant differences between exercise time points.

$8(p<0.001)$ weeks of training when compared to pre-exercise, whereas compared to after an exercise session at the beginning of training, there was a significant decrease in the MDA level after 4 $(p<0.001)$ and $8(p<0.001)$ weeks of training (Figure $1 \mathrm{a})$. Blood lactate concentration was highest after an exercise session at the beginning of training. We noted that lactate concentrations had significantly increased after an exercise session at the beginning of training $(p<0.001)$ after $4(p<0.001)$ and $8(p<0.001)$ weeks of training when compared to pre-exercise. Additionally, after exercise training, lactate concentration was significantly lower after $4(p=0.009)$ and $8(p=0.004)$ weeks of training than after an exercise session at the beginning of training (Figure 1b). No significant CK changes were seen ( $p=0.104)$ (Figure 1c).

Hs-CRP levels were highest after an exercise session at the beginning of training. The levels tended to decrease after 4 weeks of training. Subsequently, after 8 weeks of training a continuous decrease in most subjects was revealed, but in some of them there was an increment in hs-CRP level, as shown in Figure 2.

There tended to be a positive association between MDA and lactate concentration levels $(\mathrm{r}=0.43, p=0.061)$ and $\Delta$ Eight-Acute MDA level and $\Delta$ Eight-Acute lactate concentration level $(r=0.38$, $p=0.097$ ) after 8 weeks of training.

The correlation analyses between hs-CRP and body compositions, and lipid and lipoprotein levels, showed a positive 


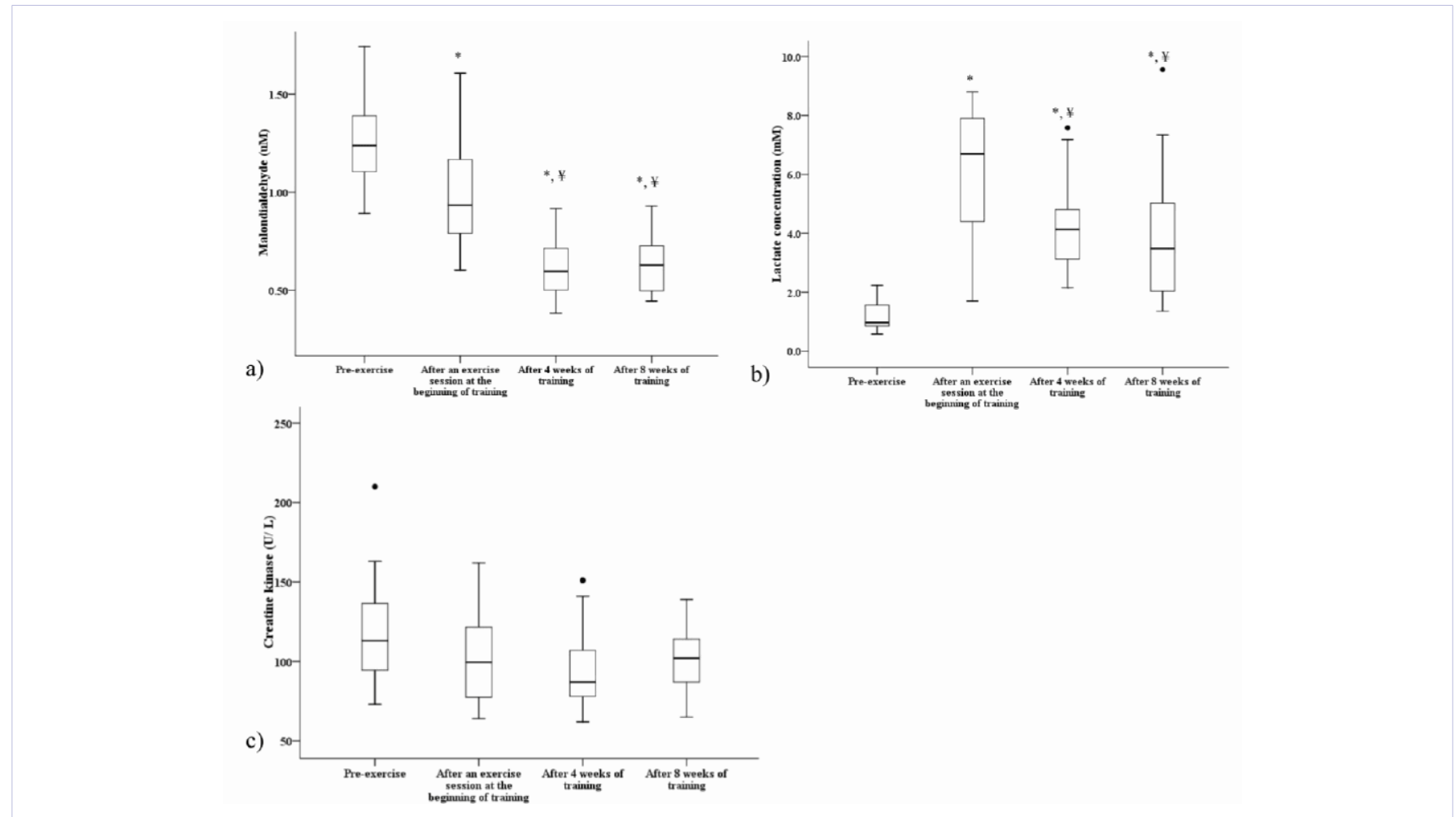

Figure 1: Biochemical levels in pre-exercise, after an exercise session at the beginning of training, and after 4 and 8 weeks of training; a) Malondialdehyde level, b) Lactate concentration level and c) Creatine kinase level.

$*=$ Significant different from pre-exercise, $p<0.05,{ }^{*}=$ Significant different from after an exercise session at the beginning of training, $p<0.05$.

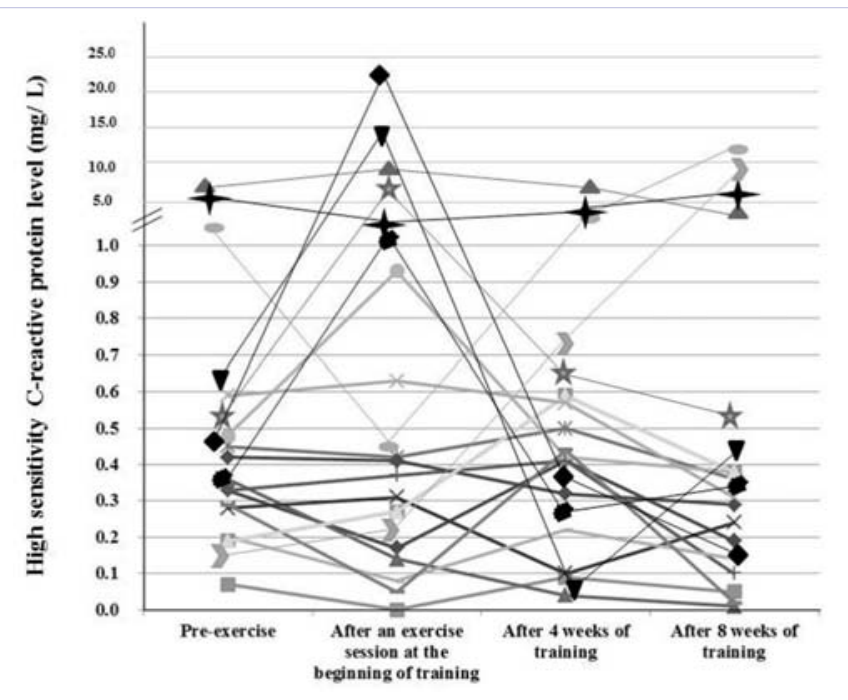

Figure 2: High sensitivity C-reactive protein level of each participant (N $=20$ ) at the different exercise periods

correlation between hs-CRP and weight, and also body fat, BMI, TG and lean body mass. On the other hand, hs-CRP after 4 and 8 weeks of training indicated negative correlations with HDL-C level after 4 and 8 weeks of training ( $\mathrm{r}=-0.45, p=0.047$ and $\mathrm{r}=$ $-0.62, p=0.004$, respectively), as presented in table 4 .

\section{Discussion}

The present study shows that oxidative stress markers had decreased immediately after exercise at the beginning of training and were more pronounced after 4 and 8 weeks of training. The highest lactic acid level was measured immediately after exercise at the beginning of training and then continuously declined during the training programme. A similar course (not significant) has been observed for hs-CRP. The nutritional status and lipid profiles did not change with the exercise intervention.

Reduced MDA levels after exercise training have also been reported by previous studies [21]. The decline in MDA levels is compatible with the notion of Lovlin et al., who suggested that exercise training at $40 \% \mathrm{VO}_{2}$ max reduces plasma MDA levels and exercising at $70 \% \mathrm{VO}_{2}$ max results in MDA levels even below resting values. They proposed that submaximal exercise training may prevent the increase in MDA and lipid peroxidation [22]. A possible explanation could be that lactate metabolism and changes in the NADH/ NADPH ratio may be associated with tissue adaptive response to exercise [23,24]. For instance, lactate uptake has been shown to increase by warming down with pedalling at around $40 \% \mathrm{VO}_{2} \max$ [25]. The enhancement of lactate uptake by submaximal exercise would develop an increase in NADH/ NADPH, which possibly elevates antioxidant enzyme activity. Consequently, substrates able to produce free radicals are decreased [22]. Although we do not have lactate uptake 
Table 4: Correlations between high sensitivity C-reactive protein, creatine kinase, body compositions, and lipid and lipoprotein levels

\begin{tabular}{|c|c|c|}
\hline Correlations & $\mathbf{r}$ & $p$ \\
\hline CK and weight at pre-exercise & 0.48 & 0.034 \\
\hline CK and lean body mass at pre-exercise & 0.68 & 0.001 \\
\hline $\begin{array}{l}\mathrm{CK} \text { and cholesterol after an exercise session at the } \\
\text { beginning of training }\end{array}$ & 0.49 & 0.028 \\
\hline $\begin{array}{l}\text { CK and WHR after an exercise session at the beginning } \\
\text { of training }\end{array}$ & 0.46 & 0.042 \\
\hline CK and lean body mass after 4 weeks of training & 0.58 & 0.007 \\
\hline Hs-CRP and weight at pre-exercise & 0.54 & 0.014 \\
\hline Hs-CRP and body fat at pre-exercise & 0.71 & $<0.001$ \\
\hline Hs-CRP and BMI at pre-exercise & 0.61 & 0.005 \\
\hline $\begin{array}{l}\text { Hs-CRP and HDL-C after an exercise session at the } \\
\text { beginning of training }\end{array}$ & -0.45 & 0.048 \\
\hline $\begin{array}{l}\text { Hs-CRP and BMI after an exercise session at the } \\
\text { beginning of training }\end{array}$ & 0.45 & 0.044 \\
\hline Hs-CRP and weight after 4 weeks of training & 0.57 & 0.008 \\
\hline Hs-CRP and HDL-C after 4 weeks of training & -0.45 & 0.047 \\
\hline Hs-CRP and body fat after 4 weeks of training & 0.75 & $<0.001$ \\
\hline Hs-CRP and BMI after 4 weeks of training & 0.66 & 0.002 \\
\hline Hs-CRP and weight after 8 weeks of training & 0.56 & 0.010 \\
\hline Hs-CRP and HDL-C after 8 weeks of training & -0.62 & 0.004 \\
\hline Hs-CRP and TG after 8 weeks of training & 0.52 & 0.019 \\
\hline Hs-CRP and WHR after 8 weeks of training & 0.74 & $<0.001$ \\
\hline Hs-CRP and BMI after 8 weeks of training & 0.51 & 0.022 \\
\hline Hs-CRP and lean body mass after 8 weeks of training & 0.65 & 0.002 \\
\hline
\end{tabular}

Based on Pearson's correlation, significant correlated at $p<0.05$.

measurements, we demonstrated a continuous drop in lactate concentration after exercise training and a tendency for a positive correlation between MDA levels and lactate concentrations.

The lower blood lactate concentrations observed after training in the present study could be due to several reasons. Firstly, a muscle glycogen sparing effect during exercise may have developed due to an increased use of fatty acids instead of carbohydrate [26]. Jackman and Willis noted that low-intensity endurance exercise mainly involved slow oxidative type I muscle fibres, indicating the preferential use of fat oxidation [27]. Another reason may be an increasing lactate uptake during submaximal exercise after training [25].

In line with our findings, Fredsted et al. did not see increased CK levels immediately after exercise when compared to preexercise [28]. They showed the highest CK levels during the 3 days post-exercise [28]. Muscle damage after exercise results in the release of various types of skeletal muscle protein to the blood and CK activity levels have been used as a marker of cell disruption and increased membrane permeability [29]. However, CK levels increase not earlier than several hours post-exercise. The observed association between CK and lean body mass is also compatible with previous studies $[30,31]$. Thus, the active muscle mass, exercise intensity and training status may all influence CK level [32].

Although hs-CRP levels did not differ significantly between time points, the highest levels tended to appear after exercise at the beginning of training followed by a subsequent decline after 4 and 8 weeks of training. Similar findings have been reported by Marcell et al. [33] and Fairey et al. [34] who did not find significant differences in hs-CRP levels between baseline and after exercise training. The tendency of hs-CRP to decline in our study was also consistent with previous studies, demonstrating lower CRP levels after training in healthy males for 9 months [7] as well as in patients with intermittent claudication [35]. These authors suggested that metabolic adaptation from oxygen utilization in muscle [35] as a result of regular exercise training might reduce inflammatory responses and develop an antioxidative defence function $[7,35]$. In contrast, You et al. found that postmenopausal women, who had diet-induced weight loss, did not show lower CRP levels. However, when exercise training and dieting were combined, significantly reduced CRP levels were seen [36]. Previous study showed that obesity associated with inflammation and oxidative stress caused nuclear factor$\kappa \mathrm{B}$-activated inflammation [9]. Also, the present study indicates a positive correlation between hs-CRP level and parameters of lipids and body compositions. Taken together, exercise training might cause beneficial effects by reducing inflammation markers (hs-CRP).

Our data from lipid and lipoprotein levels are in agreement with Kraus et al. who did not see any difference in cholesterol, HDL-C and LDL-C after 8 months of exercise with low-amount moderate-intensity training [37]. These authors suggested that the amount of exercise was more important in relation to lipid and lipoprotein responses than the intensity of exercise [37]. Also, nutritional status in our study was compatible with the findings of Devries et al. who demonstrated no change in body weight and body fat percentage in women after endurance training for 12 weeks [38]. They suggested that high-intensity exercise could change body composition [39]. Previous studies showed an association between lean body mass and protein intake $[40,41]$. Collectively, our findings suggest that low-intensity exercise training may not affect lipid and lipoprotein levels or nutritional status but showed other clinically relevant effects as a consequence of exercise training in previously sedentary subjects, i.e. lowering of oxidative stress levels.

Several limitations of this study have to be mentioned. Firstly, the timing of blood sampling is crucial, e.g. for CK levels, as reported by Fredsted et al. [28]. Secondly, information on antioxidant levels for illustrating the redox alteration is missing. Thirdly, the sample size is relatively small due to the long duration of exercise training.

\section{Conclusion}

The present findings indicate beneficial effects of lowintensity endurance training on oxidative stress (decreased MDA levels). Interestingly, the exercise training seems (tendency) to decrease inflammation responses and likely associated with 
nutritional status alteration during exercise training. Thus, sedentary subjects may clearly benefit from low-intensity exercise through adaptive responses to oxidative stress and improved exercise tolerance.

\section{Acknowledgements}

This work is supported by a National Research Council of Thailand, Burapha University grant (grant number 113/2556) and a Faculty of Allied Health Science, Burapha University grant. The authors also gratefully thank Dr. Worachote Boonsriwong for his help and encouragement.

\section{References}

1. Duran FS, Lugo L, Ramirez L, Eusse E. Effects of an exercise program on the rehabilitation of patients with spinal cord injury. Arch Phys Med Rehabil. 2001;82(10):1349-1354. doi: S0003999301870787 [pii]

2. Armstrong RB, Ogilvie RW, Schwane JA. Eccentric exercise-induced injury to rat skeletal muscle. J Appl Physiol Respir Environ Exerc Physiol. 1983;54(1):80-93.

3. Kim JD, Yu BP, McCarter RJ, Lee SY, Herlihy JT. Exercise and diet modulate cardiac lipid peroxidation and antioxidant defenses. Free Radic Biol Med. 1996;20(1):83-88. doi: 0891584995020233 [pii]

4. Navarro A, Gomez C, Lopez-Cepero JM, Boveris A. Beneficial effects of moderate exercise on mice aging: survival, behavior, oxidative stress, and mitochondrial electron transfer. Am J Physiol Regul Integr Comp Physiol. 2004;286(3):R505-511. doi: 10.1152/ ajpregu.00208.2003

5. Reimers CD, Knapp G, Reimers AK. Does physical activity increase life expectancy? A review of the literature. J Aging Res. 2012;2012(11):243958. doi: 10.1155/2012/243958

6. Gomez-Cabrera M-C, Domenech E, Viña J. Moderate exercise is an antioxidant: Upregulation of antioxidant genes by training. Free Radic Biol Med. 2008;44(2):126-131. doi: 10.1016/j. freeradbiomed.2007.02.001

7. Mattusch F, Dufaux B, Heine O, Mertens I, Rost R. Reduction of the plasma concentration of C-reactive protein following nine months of endurance training. Int J Sports Med. 2000;21(1):21-24. doi: 10.1055/ s-2000-8852

8. Kasapis C, Thompson PD. The effects of physical activity on serum C-reactive protein and inflammatory markers: a systematic review. J Am Coll Cardiol. 2005;45(10):1563-1569. doi: 10.1016/j. jacc.2004.12.077

9. Fernandez-Sanchez A, Madrigal-Santillan E, Bautista M, et al. Inflammation, oxidative stress, and obesity. Int J Mol Sci. 2011;12(5):3117-3132. doi: 10.3390/ijms12053117

10. Achten J, Gleeson M, Jeukendrup AE. Determination of the exercise intensity that elicits maximal fat oxidation. Med Sci Sports Exerc. 2002;34(1):92-97.

11. Febbraio MA. Alterations in energy metabolism during exercise and heat stress. Sports Med. 2001;31(1):47-59.

12. Brooks GA, Butterfield GE, Wolfe RR, et al. Increased dependence on blood glucose after acclimatization to 4,300 m. J Appl Physiol (1985). 1991;70(2):919-927.

13. Karvonen MJ, Kentala E, Mustala 0. The effects of training on heart rate; a longitudinal study. Ann Med Exp Biol Fenn. 1957;35(3):307315.
14. Inoue S, Zimmet P, Chen C, Ikeda Y. WHO Western Pacific Reigon. The Asia-Pacific perspective: redefining obesity and its treatment. Health Communication Australia, Australia Pty Ltd. 2000.

15. WHO. Obesity: preventing and managing the global epidemic. Report of a WHO consultation. World Health Organization (WHO). 2000a;894:1-253.

16. Friedewald WT, Levy RI, Fredrickson DS. Estimation of the concentration of low-density lipoprotein cholesterol in plasma, without use of the preparative ultracentrifuge. Clin Chem. 1972;18(6):499-502.

17. Nielsen F, Mikkelsen BB, Nielsen JB, Andersen HR, Grandjean P. Plasma malondialdehyde as biomarker for oxidative stress: reference interval and effects of life-style factors. Clin Chem. 1997;43(7):12091214.

18. Tsai LY, Lee KT, Tsai SM, Lee SC, Yu HS. Changes of lipid peroxide levels in blood and liver tissue of patients with obstructive jaundice. Clin Chim Acta. 1993;215(1):41-50.

19. Sekeroglu MR, Aslan R, Tarakcioglu M, Bayiroglu F, Meral I. Effect of acute and regular exercise on antioxidative enzymes, tissue damage markers and membran lipid peroxidation of erythrocytes in sedentary students. Turk J Med Sci. 1998;28:411-414.

20. Cohen J. Statistical power analysis for the behavioral sciences. 2nd, editor. Hillsdale, NJ: Lawrence Earlbaum Associates; 1988.

21. Javier Ordonez F, Rosety-Rodriguez M. Regular exercise attenuated lipid peroxidation in adolescents with Down's syndrome. Clin Biochem. 2007;40(1-2):141-142. doi: 10.1016/j.clinbiochem.2006.09.013

22. Lovlin R, Cottle W, Pyke I, Kavanagh M, Belcastro AN. Are indices of free radical damage related to exercise intensity. Eur J Appl Physiol Occup Physiol. 1987;56(3):313-316.

23. Bonen A, Campbell CJ, Kirby RL, Belcastro AN. A multiple regression model for blood lactate removal in man. Pflugers Arch. 1979;380(3):205-210.

24. Ivy JL, Withers RT, Van Handel PJ, Elger DH, Costill DL. Muscle respiratory capacity and fiber type as determinants of the lactate threshold. J Appl Physiol Respir Environ Exerc Physiol. 1980;48(3):523-527.

25. McLellan TM, Skinner JS. Blood Lactate Removal During Active Recovery Related to the Aerobic Threshold. Int J Sports Med. 1982;3 (4):224-229. doi: 10.1055/s-2008-1026092

26. Young AJ, Evans WJ, Cymerman A, Pandolf KB, Knapik JJ, Maher JT. Sparing effect of chronic high-altitude exposure on muscle glycogen utilization. J Appl Physiol Respir Environ Exerc Physiol. 1982;52(4):857-862.

27. Jackman MR, Willis WT. Characteristics of mitochondria isolated from type I and type IIb skeletal muscle. Am J Physiol. 1996;270 (2 Pt 1):C673-678.

28. Fredsted A, Clausen T, Overgaard K. Effects of step exercise on muscle damage and muscle Ca2+ content in men and women. J Strength Cond Res. 2008;22(4):1136-1146. doi: 10.1519/JSC.0b013e318173db9b

29. Van der Meulen JH, Kuipers H, Drukker J. Relationship between exercise-induced muscle damage and enzyme release in rats. J Appl Physiol (1985). 1991;71(3):999-1004.

30. Novak LP, Tillery GW. Relationship of serum creatine phosphokinase to body composition. Hum Biol. 1977;49(3):375-380. 
31. Swaminathan R, Ho CS, Donnan SP. Body composition and plasma creatine kinase activity. Ann Clin Biochem. 1988;25 ( Pt 4):389-391. doi: $10.1177 / 000456328802500411$

32. Klapcinska B, Iskra J, Poprzecki S, Grzesiok K. The effects of sprint $(300 \mathrm{~m})$ running on plasma lactate, uric acid, creatine kinase and lactate dehydrogenase in competitive hurdlers and untrained men. J Sports Med Phys Fitness. 2001;41(3):306-311.

33. Marcell TJ, McAuley KA, Traustadottir T, Reaven PD. Exercise training is not associated with improved levels of C-reactive protein or adiponectin. Metabolism. 2005;54(4):533-541. doi: S0026049504004329 [pii] 10.1016/j.metabol.2004.11.008

34. Fairey AS, Courneya KS, Field CJ, et al. Effect of exercise training on C-reactive protein in postmenopausal breast cancer survivors: a randomized controlled trial. Brain Behav Immun. 2005;19(5):381388. doi: S0889-1591(05)00068-1 [pii] 10.1016/j.bbi.2005.04.001

35. Tisi PV, Hulse M, Chulakadabba A, Gosling P, Shearman CP. Exercise training for intermittent claudication: Does it adversely affect biochemical markers of the exercise-induced inflammatory response? Eur J Vasc Endovasc Surg. 1997;14(5):344-350. doi: 10.1016/S10785884(97)80283-3

36. You T, Berman DM, Ryan AS, Nicklas BJ. Effects of hypocaloric diet and exercise training on inflammation and adipocyte lipolysis in obese postmenopausal women. J Clin Endocrinol Metab. 2004;89(4):17391746. doi: $10.1210 /$ jc.2003-031310

37. Kraus WE, Houmard JA, Duscha BD, et al. Effects of the amount and intensity of exercise on plasma lipoproteins. N Engl J Med. 2002;347(19):1483-1492. doi: 10.1056/NEJMoa020194

38. Devries MC, Hamadeh MJ, Glover AW, Raha S, Samjoo IA, Tarnopolsky MA. Endurance training without weight loss lowers systemic, but not muscle, oxidative stress with no effect on inflammation in lean and obese women. Free Radic Biol Med. 2008;45(4):503-511. doi:10.1016/j.freeradbiomed.2008.04.039

39. Kemmler W, von Stengel S, Engelke K, Haberle L, Mayhew JL, Kalender WA. Exercise, body composition, and functional ability: a randomized controlled trial. Am J Prev Med. 2010;38(3):279-287. doi: 10.1016/j. amepre.2009.10.042

40. Geirsdottir OG, Arnarson A, Ramel A, Jonsson PV, Thorsdottir I. Dietary protein intake is associated with lean body mass in communitydwelling older adults. Nutr Res. 2013;33(8):608-612. doi: 10.1016/j. nutres.2013.05.014

41. Bopp MJ, Houston DK, Lenchik L, Easter L, Kritchevsky SB, Nicklas BJ. Lean Mass Loss Is Associated with Low Protein Intake during DietaryInduced Weight Loss in Postmenopausal Women. J Am Diet Assoc. 2008 Jul;108(7):1216-20. doi: 10.1016/j.jada.2008.04.017 